\title{
Diferenciais de mortalidade: níveis e padrões segundo o sexo no município de São Paulo de 1920 a 2005
}

\author{
Pamila Cristina Lima Siviero* \\ Cássio Maldonado Turra** \\ Roberto do Nascimento Rodrigues ${ }^{\star * *}$
}

\begin{abstract}
O objetivo deste trabalho é analisar, de forma sistemática, os níveis e padrões do diferencial de mortalidade entre os sexos no município de São Paulo, ao longo de 85 anos, de 1920 a 2005. São utilizados três indicadores na análise: o hiato na esperança de vida ao nascer; a razão de sexo entre taxas específicas de mortalidade por idade; e a contribuição de diferentes idades no hiato na esperança de vida ao nascer, com base no método de decomposição da diferença entre esperanças de vida ao nascer proposto pela ONU (1982). De maneira geral, as tendências de período observadas no município de São Paulo são semelhantes àquelas verificadas em países desenvolvidos, com algumas especificidades. Quanto à tendência de longo prazo do nível do diferencial na mortalidade por sexo, observa-se uma defasagem temporal de 30 a 50 anos. O início do processo de transição do padrão etário da mortalidade diferencial entre homens e mulheres foi tardio, mas, recentemente, as mudanças foram semelhantes às dos países desenvolvidos. Além disso, a análise da contribuição das diferentes idades para o hiato na esperança de vida ao nascer por sexo indica que a redução do diferencial observada no último quinquênio foi explicada, principalmente, pela diminuição da mortalidade masculina nas idades jovens. Entretanto, a redução no risco de morrer entre adultos e idosos também contribuiu com uma parcela significativa (cerca de $30 \%$ ) do decréscimo do diferencial de mortalidade por sexo no período. Neste sentido, os resultados aqui apresentados sugerem que o comportamento futuro dos diferenciais de mortalidade por sexo dependerá, em maior medida, da heterogeneidade no risco de morrer em idades avançadas.
\end{abstract}

Palavras-chave: Diferencial de mortalidade por sexo. Decomposição. Município de São Paulo.

\section{Introdução}

O diferencial na mortalidade por sexo é um fenômeno observado na maioria dos países e constitui um dos principais temas de pesquisa em mortalidade (LUY, 2003). Via de regra, os homens experimentam maior mor- talidade do que as mulheres, em cada idade, exceto em alguns países, especialmente naqueles situados no continente asiático. A magnitude da desvantagem masculina, entretanto, varia de acordo com as condições sociais, econômicas e ambientais. Durante grande parte do século XX, a mortalidade

\footnotetext{
* Doutoranda em Demografia (Cedeplar/UFMG), professora assistente do Instituto de Ciências Sociais Aplicadas da Unifal-MG.

** Doutor em Demografia, professor adjunto do Departamento de Demografia da UFMG.

*** Professor titular do Departamento de Demografia da UFMG e pesquisador do Cedeplar/UFMG.
} 
total declinou, as causas de óbito mudaram de transmissíveis para não transmissíveis e a desvantagem masculina continuou a crescer em muitos países industrializados. Entretanto, nos países mais desenvolvidos, desde 1970, o diferencial na esperança de vida ao nascer entre os sexos vem se estreitando (GLEI, 2005; TROVATO, 2005; PRESTON; WANG, 2006; GLEI; HORIUCH, 2007).

Os países em desenvolvimento também passaram, no século XX, pelos processos de transição da mortalidade e se encontram em estágios distintos do processo de transição epidemiológica. Mas, em muitos desses países, como no Brasil, o diferencial de mortalidade por sexo ainda não apresenta sinais inequívocos de redução (SIMÕES, 2002).

Fatores de naturezas socioeconômica, cultural, ambiental ou política podem ser arrolados para explicar o diferencial na mortalidade por sexo, além daqueles de natureza biofisiológica (KALBEN, 2000). No caso do Brasil, uma das razões evocadas tem sido o aumento da sobremortalidade masculina no segmento populacional composto por jovens e adultos, relacionado a mortes por causas externas, especialmente violências (FERREIRA; CASTINNEIRAS, 1996a, 1996b; SIMÕES, 2002; SEADE, 2006).

É possível, porém, que outros aspectos possam ser arrolados e que haja especificidades no papel de cada um deles, ao longo do tempo. Trata-se, portanto, de um campo de investigação promissor, capaz de revelar resultados importantes para o conhecimento e entendimento do fenômeno, assim como para subsidiar ações ou políticas visando a redução dessa desigualdade. A despeito de sua importância, especialmente tendo em vista a persistência ou aumento do diferencial de mortalidade por sexo, ainda são escassos os estudos nessa área focalizando o Brasil, suas unidades federativas e seus municípios.

Neste contexto, o objetivo desse trabalho é analisar, de forma sistemática, o diferencial de mortalidade entre os sexos no município de São Paulo, de 1920 a 2005, por meio de análises de período dos níveis e padrões do diferencial, além de examinar a contribuição dos diversos grupos etários para o hiato na esperança de vida ao nascer entre os sexos, ao longo deste período.

\section{Diferencial de mortalidade por sexo: níveis e padrões}

Nos países desenvolvidos, durante boa parte do século $X X$, o diferencial na esperança de vida entre homens e mulheres ampliou substancialmente em um contexto de mudanças demográficas importantes, como a redução sustentada no nível geral da mortalidade e a mudança em seu padrão etário (UNITED NATIONS, 1988). Em um segundo momento, em geral quando os países alcançaram uma etapa avançada do processo de transição da mortalidade, observou-se uma reversão desta tendência, de forma que os países passaram a experimentar redução sistemática da diferença entre as esperanças de vida de homens e de mulheres (GLEI, 2005; TROVATO, 2005; PRESTON; WANG, 2006; GLEI; HORIUCH, 2007). Esta tendência foi verificada em grande parte das nações desenvolvidas, com algumas variações, sobretudo no que diz respeito à magnitude e ao início dos processos de ampliação e redução do diferencial entre homens e mulheres.

Este processo de transição do diferencial entre os sexos da mortalidade geral nos países desenvolvidos foi acompanhado por uma mudança no padrão etário da mortalidade diferencial entre homens e mulheres. A razão de sexo entre taxas específicas de mortalidade, a cada grupo de idade especificado, é uma medida comumente utilizada para se examinar a desvantagem na mortalidade de um sexo em relação ao outro (UNITED NATIONS, 1988). Uma razão igual à unidade indica que homens e mulheres experimentam o mesmo risco de morrer em determinada idade. Quanto maior for a razão, maior é a sobremortalidade masculina. Se esse valor for menor do que a unidade, as mulheres estão em desvantagem. A curva de razões de sexo entre taxas específicas de mortalidade por idade indica o padrão etário do diferencial na mortalidade entre os sexos.

Quando o nível geral de mortalidade era alto, a desvantagem masculina em relação às mulheres era pequena em grande parte dos 
grupos etários, observando-se, em alguns países, desvantagem feminina na mortalidade, sobretudo nas idades reprodutivas. Com o aumento do diferencial na esperança de vida ao nascer entre homens e mulheres, a desvantagem masculina observada em alguns grupos etários também aumentou, gerando padrões distintos entre grupos de países. Por exemplo, entre a Primeira e a Segunda Guerras Mundiais, em alguns países, a desvantagem masculina foi mais pronunciada entre 40 e 64 anos. Outro grupo de nações, entretanto, experimentou uma razão de sexo entre taxas específicas de mortalidade - TEMs mais elevada na idade zero, enquanto outros ainda registraram desvantagem feminina na mortalidade, especialmente entre 25 e 39 anos (GLEl, 2005). O momento seguinte, contudo, caracterizou-se pela universalidade da desvantagem masculina na mortalidade, de forma que, na maioria dos países, o pico se deslocou para as idades mais jovens, entre 15 e 24 anos (GLEl, 2005; ZANFONGNON; BORBEAU, 2008).

Com a diminuição dos ganhos na esperança de vida, observa-se um processo de estabilização da desvantagem masculina nos grupos etários nos quais esta era mais pronunciada. E, nos anos mais recentes, verifica-se uma tendência de redução dos picos de sobremortalidade masculina em grande parte dos países (GLEl, 2005).

Para os países em desenvolvimento e menos desenvolvidos a situação é menos clara, sobretudo devido à ausência de dados confiáveis (LANGFORD; STOREY, 1993). A despeito desta limitação, alguns autores observaram que o diferencial na esperança de vida ao nascer entre os sexos também aumentou, em favor das mulheres, com o declínio da mortalidade (OHADIKE, 1983; VALLIN, 1983; SHRESTHA, 2000; GEE, 2002; UNITED NATIONS, 2005; 2007), com exceção de alguns países situados no continente asiático (LANGFORD; STOREY, 1993). Além disso, assim como verificado nas regiões mais desenvolvidas, a magnitude e a velocidade de aumento do diferencial diferiram, sistematicamente, entre os diversos grupos de países, sobretudo na América Latina, Sul da Ásia, África Sub-sahariana e no Extremo Oriente da Ásia (UNITED
NATIONS, 1983). No entanto, o diferencial tende a ser menor do que aquele observado nos países mais desenvolvidos (GEE, 2002; SHRESTHA, 2000; UNITED NATIONS, 2005 ; 2007) e ainda menor nas regiões menos desenvolvidas, que experimentam condições socioeconômicas e de saúde muito desfavoráveis (UNITED NATIONS, 2005; 2007). Neste sentido, há indícios de que, em tais regiões, as mulheres estão em desvantagem mesmo em um contexto de ganhos na esperança de vida similares entre homens e mulheres.

O Brasil seguiu a tendência mundial, uma vez que as mulheres apresentaram maior esperança de vida do que os homens durante a segunda metade do século $X X$ e houve uma rápida ampliação da diferença entre as esperanças de vida feminina e masculina, no conjunto do Brasil, especialmente na Região Sudeste. Entre 1940 e 2000, o hiato na esperança de vida brasileira por sexo variou de 4,41 para 7,78 anos, apresentando incrementos em todas as décadas, sendo que os maiores ganhos proporcionais ocorreram ao longo das décadas de 1940 (13\%), 1950 (13\%), 1970 (11\%) e 1980 (21\%). Nos anos 1960 e 1990, por sua vez, o incremento foi muito menor, em torno de 1\% (SIMÕES, 2002).

Entre 2000 e 2005, os diferenciais na esperança de vida entre os sexos no país mudaram pouco, passando de 7,7 para 7,6 anos nesse período (OLIVEIRA et al., 2006). O Rio de Janeiro apresentou os maiores diferenciais, tanto em 2000 (9,2 anos) quanto em 2005 (8,9 anos). O Ceará ocupa a segunda posição, em 2005 (8,8 anos), seguido por São Paulo (8,5 anos). Vale destacar ainda que, nestes três Estados, a sobremortalidade masculina diminuiu em 2005, em relação a 2000 (OLIVEIRA et al., 2006). Ao que parece, então, inicia-se um processo, já em curso nos países desenvolvidos, de redução do diferencial de mortalidade por sexo.

Por outro lado, a contribuição dos grupos etários para o diferencial na esperança de vida ao nascer nem sempre acompanhou as tendências do padrão etário do hiato. De fato, uma grande desvantagem na mortalidade em determinada idade não implica, necessariamente, uma grande contribuição 
para o diferencial total na mortalidade por sexo, ou seja, na esperança de vida. Isto porque uma razão de sexo elevada, em certo grupo etário, pode ter pouco peso em termos de número esperado de anos de vida ao nascer, se a força de mortalidade nestas idades for pequena (UNITED NATIONS, 1988; GLEl, 2005). A razão entre taxas específicas de mortalidade não leva em consideração a magnitude das taxas, ao passo que a contribuição do grupo etário para o diferencial depende desta magnitude e da posição do grupo etário no eixo das idades (UNITED NATIONS, 1988). Neste sentido, os estudos apontam para a importância da utilização de mais de uma medida na análise sistemática do diferencial na mortalidade entre os sexos, visto que a utilização somente das razões pode levar a conclusões incompletas ou até mesmo equivocadas.

\section{Material e métodos}

\section{Fonte de dados}

Os insumos necessários para se estudar o diferencial de mortalidade por sexo podem ser estimados com base em duas fontes de dados: registro de óbitos e população. Para o município de São Paulo, os dados de óbitos desagregados por sexo e grupos etários são provenientes do Registro Civil e elaborados pela Fundação Sistema Estadual de Análise de Dados (Seade), que disponibilizou a série anual para o período de 1903 a 2003. Como no momento da execução do trabalho os dados de 2004 a 2006 não estavam disponíveis na Fundação Seade, os mesmos foram obtidos no sítio eletrônico do Departamento de Informática do Sistema Único de Saúde (Datasus) e são oriundos do Sistema de Informação sobre Mortalidade (SIM).
Os dados de população presente e residente ${ }^{1}$ do município de São Paulo, para os anos de recenseamento disponíveis, ${ }^{2}$ desagregados por sexo e grupos etários, são provenientes dos censos demográficos brasileiros. Até 1960 os dados foram fornecidos pela Fundação Seade. A partir de 1970, foram utilizados os microdados disponibilizados pelo Cedeplar.

Diante das condições dos dados, optou-se por construir a série de mortalidade desagregada por sexo e grupos etários quinquenais, de 1920 até 2005, de cinco em cinco anos. Tal escolha se justifica por diversos motivos. Em primeiro lugar, partindo de 1920, elimina-se a necessidade de estimar as populações de 1905 e 1910, que seriam calculadas por meio das populações de 1890 e 1920, cuja qualidade é discutível, principalmente pela ausência de dados por sexo em 1890. Além disso, os dados de óbitos anteriores a 1918 estão muito agregados nas idades adultas, o que diminuiria a precisão das estimativas. Vale ressaltar que o período de 85 anos entre 1920 e 2005 é extenso o suficiente para permitir a análise, uma vez que incorpora as principais fases da transição de mortalidade ocorrida no município de São Paulo.

A construção da série histórica de mortalidade e das tábuas de vida de período exigiu a adoção de diversos procedimentos preliminares que não serão discutidos com detalhes nesse artigo. ${ }^{3}$ Entre eles, destacam-se: compatibilização dos dados de óbitos, no que diz respeito às (des)agregações por idade, por meio do método de interpolação osculatória de Karup-King; uniformização do grupo etário aberto em 80 anos e mais; estimação das populações dos anos intercensitários e de 1930, ano em que não houve recenseamento; desagregação dos dados de população, de forma que ficassem consistentes com a desagrega-

\footnotetext{
${ }^{1}$ Até 1960 a informação mais confiável era aquela disponibilizada para a população presente, embora a partir de 1940 fosse possível recuperar a população residente. A partir de 1970, a população era a residente.

2 1872, 1890, 1920, 1940, 1950, 1960, 1970, 1980, 1991 e 2000. A Fundação Seade não disponibilizou os dados de 1900 , uma vez que para este ano o IBGE somente divulgou dados de população desagregados por idade e sexo para o conjunto da população brasileira e suas unidades federativas, mas não em nível de municípios ou capitais.

3 Para mais detalhes, ver Siviero (2009).
} 
ção dos óbitos; correção do fenômeno da "invasão de óbitos", visto que, até 1969, o registro de óbitos do município de São Paulo era realizado segundo o local de ocorrência e não com base no local de residência do falecido; e, finalmente, avaliação e correção do sub-registro das taxas de mortalidade. Após a aplicação de todos esses procedimentos, as funções de mortalidade, por sexo e grupos etários quinquenais, de 1920 a 2005 , foram construídas.

\section{Aspectos metodológicos}

Em termos gerais, muitos estudos sobre diferenciais de mortalidade por sexo utilizam a análise de indicadores como razões ou diferenças entre taxas de mortalidade, além da comparação entre esperanças de vida ao nascer. Pollard (1983) apresenta um exemplo bastante claro de como a análise pode não ser consistente se tais medidas forem utilizadas sozinhas. Empregando os mesmos dados, o autor calculou dois indicadores distintos do diferencial (razão e diferença entre as taxas masculina e feminina de mortalidade) e observou que a razão aumenta, ao passo que a diferença diminui. A esperança de vida, por outro lado, apesar de ser uma medida-resumo do nível geral da mortalidade que pode ser comparada, apresenta complicações quando o objeto de estudo é a análise de diferenciais. Reduções iguais na força da mortalidade, em duas populações distintas, podem causar um aumento no diferencial entre esperanças de vida ao nascer. Assim, é perfeitamente possível observar populações com diferenciais, mensurados em termos da força da mortalidade, se reduzindo ao longo do tempo e, ao mesmo tempo, um aumento no hiato entre as esperanças de vida (POLLARD, 1983).

Alguns trabalhos vêm complementando a análise descritiva do diferencial com métodos que mensuram a contribuição de grupos etários para o hiato na expectativa de vida ao nascer por sexo (UNITED NATIONS, 1988; GLEI, 2005; TROVATO, 2005; GLEl; HORIUCH, 2007). Seguindo essa linha, três indicadores foram utilizados na análise nesse trabalho:
- a diferença entre as esperanças de vida ao nascer feminina e masculina, como um indicador do diferencial total na mortalidade por sexo;

- razões de sexo entre taxas específicas de mortalidade por idade $\left(\mathrm{n}_{\mathrm{TEM}}\right.$ masc. $/ \mathrm{nTEM}_{\mathrm{X}}$ fem.), para verificar tendências do padrão etário no diferencial da mortalidade entre homens e mulheres;

- método de decomposição da diferença entre esperanças de vida ao nascer feminina e masculina, com o intuito de complementar a análise descritiva do diferencial, feita por meio dos indicadores citados acima, e solucionar os problemas a eles relacionados.

Decomposição da diferença entre expectativas de vida ao nascer

Como visto anteriormente, a esperança de vida e as razões de sexo entre taxas apresentam alguns problemas quando o objetivo do estudo é a análise de diferenciais de mortalidade. Nesse sentido, outro aspecto da análise de mortalidade é estimar e/ou entender a contribuição da variação da mortalidade em cada grupo etário para a variação total na esperança de vida, ou seja, a decomposição da variação. Uma mudança na esperança de vida não significa, necessariamente, que as taxas de mortalidade mudam na mesma magnitude ou até na mesma direção em todas as idades. De modo geral, muitos grupos etários registrarão declínio na mortalidade e contribuirão para o aumento da esperança de vida. Por outro lado, para alguns grupos etários, a mortalidade pode aumentar e, com isso, reduzir ou neutralizar o aumento da esperança de vida. É o caso de alguns países desenvolvidos e em desenvolvimento, entre os quais o Brasil. Também é útil explicar ou decompor diferenças entre esperanças de vida pertencentes a duas populações, entre mulheres e homens, por exemplo, com relação ao diferencial de mortalidade em cada idade (ARRIAGA, 1984).

Diversos métodos de decomposição em demografia estão disponíveis na literatura internacional (KITAGAWA, 1955; POLLARD, 1983; ARRIAGA, 1984; SÁNCHEZ; PRES- 
TON, 2007, entre outros). Murthy (2005) comparou vários métodos de decomposição de mudanças na esperança de vida ao nascer e diferenciais em tais esperanças. Seu estudo teve como objetivo comparar o sistema adotado por Chandra Sekar, em 1949, com diversas metodologias, como aquelas sugeridas por Lopez e Ruzicka em 1977, Pollard em 1982 e Arriaga em 1984. Murthy (2005) demonstrou que todas as técnicas de decomposição, quando utilizadas em sua forma modificada, produzirão resultados semelhantes aos de métodos mais simples. Assim, o autor defende a utilização de métodos simples, como, por exemplo, aquele utilizado pelas United Nations (1982). Diante de tais condições, optou-se por aplicar tal método neste trabalho.

$\mathrm{O}$ método proposto pelas United $\mathrm{Na}$ tions (1982) parte da definição matemática da esperança de vida ao nascer, dependente da função da probabilidade acumulada de sobrevivência, e do fato de que a mortalidade em determinado grupo etário afetará a sobrevivência dos grupos etários subsequentes. A proposta é mensurar a contribuição de cada intervalo etário para a diferença observada entre duas esperanças de vida. Inicialmente, o método foi proposto e desenvolvido para decompor a variação entre a esperança de vida ao nascer de uma população entre dois pontos distintos no tempo. Posteriormente, as United Nations (1988) aplicaram a mesma técnica para mensurar a contribuição de cada grupo etário para o diferencial na esperança de vida por sexo, ou seja, entre duas populações em um mesmo ponto no tempo.

Após diversas manipulações algébricas e desagregações por idade da definição matemática da esperança de vida (equação 1), as equações propostas pelo método, na forma discreta (equações 2, 3 e 4), são:

$$
e_{0}=\int_{0}^{\infty} p(a) d a
$$

Para o primeiro intervalo etário:

$$
{ }_{n} \Delta_{0}=\left(e_{0}^{f}-e_{0}^{m}\right)-\left[e_{0+n}^{f}-e_{0+n}^{m} \cdot \frac{\left(l_{0+n}^{f}-l_{0+n}^{m}\right)}{2}\right]
$$

Para o intervalo etário intermediário:

$$
{ }_{n} \Delta_{x}=\left[\left(e_{x}^{f}-e_{x}^{m}\right) \cdot \frac{\left(l_{x}^{f}-l_{x}^{m}\right)}{2}\right]-\left[\left(e_{x+n}^{f}-e_{x+n}^{m}\right) \cdot \frac{\left(l_{x+n}^{f}-l_{x+n}^{m}\right)}{2}\right]
$$

Para o intervalo aberto:

$$
{ }_{\infty} \Delta_{80}=\left(e_{80}^{f}-e_{80}^{m}\right) \frac{\left(l_{80}^{f}-l_{80}^{m}\right)}{2}
$$

Onde:

$\mathrm{e}_{\mathrm{x}}$ é a esperança de vida à idade exata $\mathrm{x}$; p(a) corresponde à probabilidade de sobrevivência do nascimento até a idade exata a;

${ }_{n} \Delta_{x}$ é a contribuição da mortalidade diferencial do grupo etário $\mathrm{x}$ e $(\mathrm{x}+\mathrm{n})$ para o hiato na esperança de vida ao nascer por sexo;

$\mathrm{I}_{\mathrm{x}}$ refere-se ao número de sobreviventes à idade exata $\mathrm{x}$ na tábua de vida.

\section{Resultados}

\section{O diferencial por sexo na esperança de vida ao nascer}

Uma forma simples e direta de se observar o diferencial de mortalidade por sexo é por meio de uma inspeção visual de seus níveis. Os Gráficos 1 e 2 sumarizam a evolução do hiato na esperança de vida entre os sexos, no município de São Paulo. O Gráfico 1 relaciona as tendências de longo prazo do diferencial à evolução dos níveis de esperança de vida feminina, da mesma forma que a análise proposta por Vallin (1983). No Gráfico 2, observa-se a evolução do diferencial de mortalidade por sexo ao longo do tempo, independentemente do nível da mortalidade, assim como proposto por outros autores (GLEI, 2005; GLEI; HORIUCH, 2007).

No início da transição da mortalidade no município, entre 1920 e 1930, o diferencial se manteve em torno dos seis anos, quando a esperança de vida feminina variava de 35 a 45 anos. Entre 1935 e 1940, o diferencial diminuiu aproximadamente dois anos, mantendo-se relativamente constante até 1960. A partir de então, até 1995, o hiato experimentou um sustentado aumento, alcançando 11 anos, até a esperança de 


\section{GRÁFICO 1}

Evolução dos diferenciais na esperança de vida ao nascer por sexo, segundo o nível de mortalidade feminina Município de São Paulo - 1920-2005

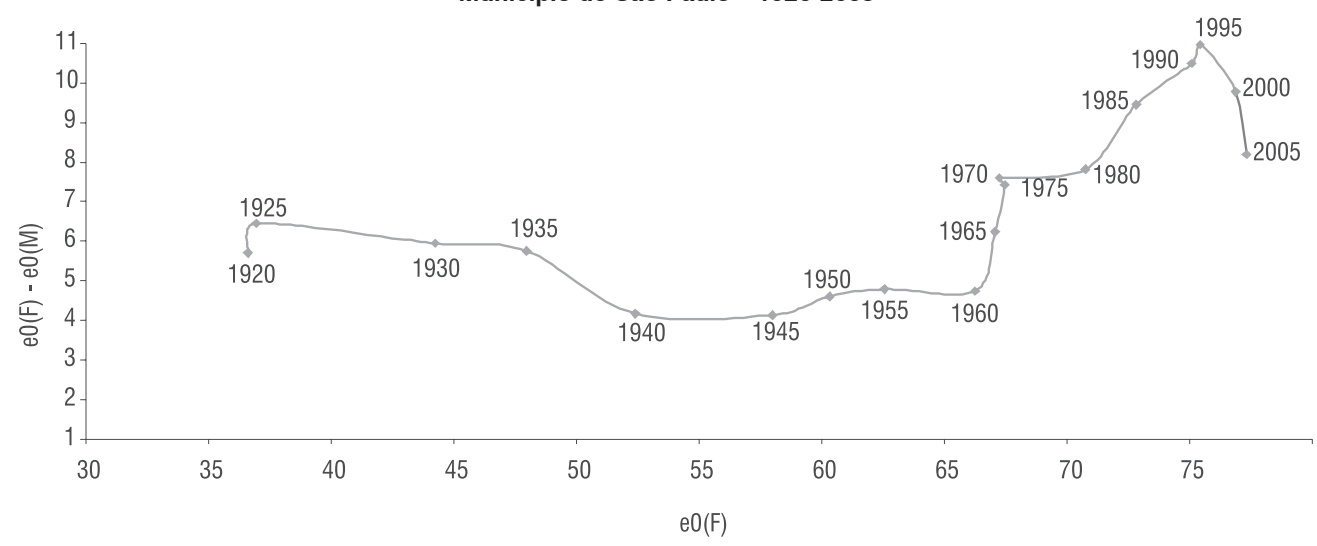

Fonte: Fundação Sistema Estadual de Análise de Dados - Seade; Departamento de Informática do Sistema Único de Saúde Datasus; Centro de Desenvolvimento e Planejamento Regional - Cedeplar/UFMG.

\section{GRÁFICO 2}

Evolução dos diferenciais na esperança de vida ao nascer por sexo Município de São Paulo - 1920-2005

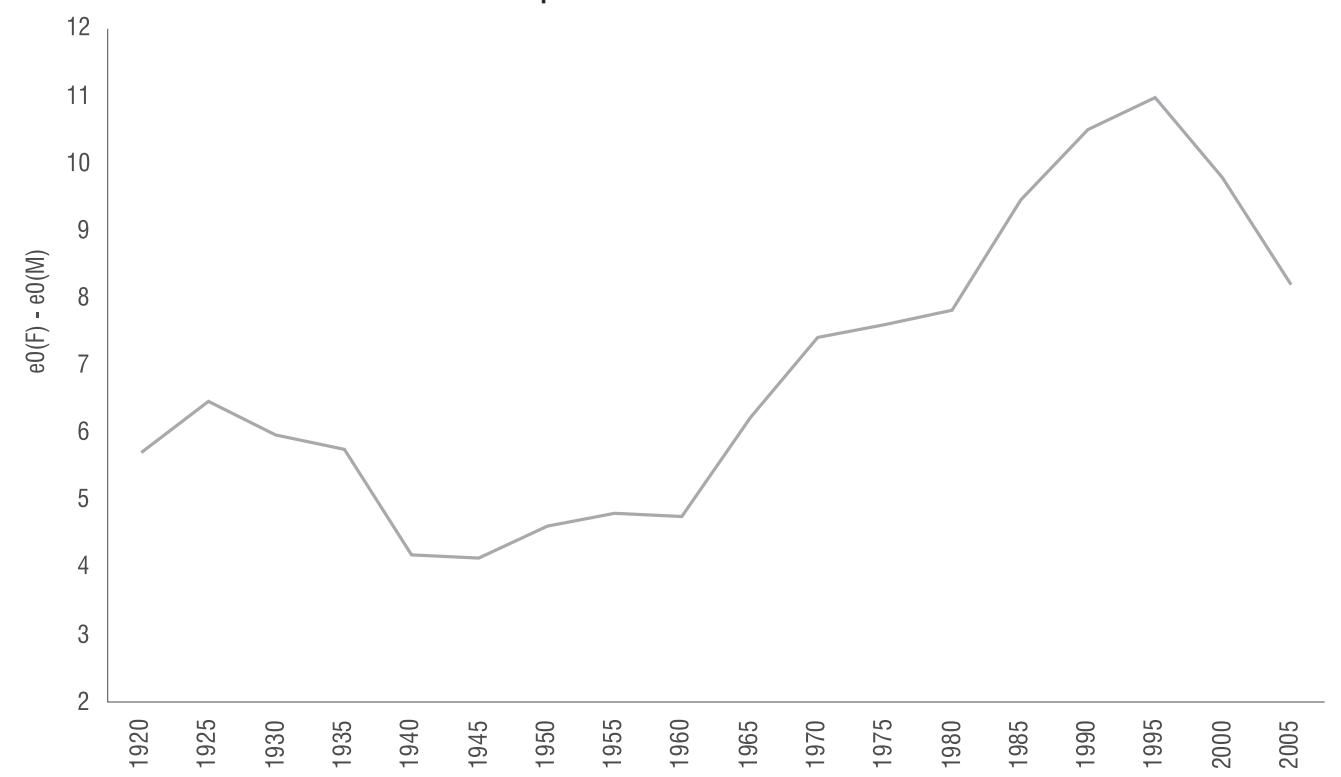

Fonte: Fundação Sistema Estadual de Análise de Dados - Seade; Departamento de Informática do Sistema Único de Saúde Datasus; Centro de Desenvolvimento e Planejamento Regional - Cedeplar/UFMG.

vida feminina atingir cerca de 75 anos. A partir de 1995, o diferencial mostrou os primeiros sinais de redução, tendência que se manteve nos quinquênios seguintes (Gráficos 1 e 2).

\section{Padrão etário do hiato na mortalidade entre os sexos}

Para entender a relação do hiato na esperança de vida entre os sexos e a desvan- 
tagem masculina na mortalidade por idade no município de São Paulo, realizou-se uma análise do comportamento do padrão etário do diferencial na mortalidade entre homens e mulheres, ao longo do período 1920-2005. No entanto, alguns períodos mais curtos também foram examinados (1925-1930; 1960-1965 e 2000-2005), visto que apresentaram especificidades na análise anterior.

A queda da mortalidade por idade, de 1920 a 2005, pode ser analisada por meio das funções de mortalidade de tais períodos (dados não apresentados). O processo de transição da mortalidade foi mais homogêneo para as mulheres, visto que se registrou redução na mortalidade em praticamente todas as idades e anos calendários. No caso masculino, sobretudo a partir dos anos 1980, o aumento da mortalidade nas idades jovens ocasionou grandes mudanças no padrão etário, que distorceram o padrão da mortalidade masculina e o diferenciaram fortemente do padrão etário feminino.

Com o intuito de entender, de forma mais sistemática, o diferencial na mortalidade entre os sexos, por grupo etário, examinaram-se as razões de sexo entre TEMs. No município de São Paulo, a desvantagem masculina já era observada desde 1920, em todos os anos e em praticamente todos os grupos etários e, nas últimas décadas, sobretudo entre os jovens adultos (Tabela 1).

Até 1950, o padrão etário do diferencial de mortalidade por sexo, mensurado por meio das razões, seguiu um padrão semeIhante: varia pouco nas idades jovens, em torno de 1 e 1,4; apresenta um pico nas idades adultas (entre os 50 e 60 anos); e diminui nas mais avançadas. Vale destacar que, em 1920, há um pico no grupo etário 10-14 anos. Entre os padrões observados na literatura, picos neste grupo etário estão associados, em geral, à elevação na mortalidade masculina, mas, no caso do município de São Paulo, isso é consequência da pequena TEM feminina observada neste ano, quando comparada aos níveis de mortalidade experimentados pelas mulheres nos grupos etários vizinhos (Gráfico 3). Neste trabalho, as taxas de mortalidade foram calculadas por meio de médias móveis trienais dos óbitos. Assim, é improvável que este comportamento observado seja reflexo de algum distúrbio ocorrido na mortalidade feminina em 1920.

Em 1960, 1965 e 1970, o padrão etário do diferencial tem a forma de um "U" invertido e a desvantagem masculina nas idades

TABELA 1

Razões entre taxas específicas de mortalidade masculina e feminina Município de São Paulo - 1920-2005

\begin{tabular}{|c|c|c|c|c|c|c|c|c|c|c|c|c|c|c|c|c|c|c|}
\hline Grupos et & 1920 & 1925 & 1930 & 1935 & 1940 & 1945 & 1950 & 1955 & 1960 & 1965 & 1970 & 1975 & 1980 & 1985 & 1990 & 1995 & 2000 & 2005 \\
\hline $0-4$ anos & 1,18 & 1,21 & 1,19 & 1,18 & 1,09 & 1,11 & 1,10 & 1,11 & 1,09 & 1,18 & 1,22 & 1,26 & 1,28 & 1,29 & 1,14 & 1,19 & 1,08 & 1,17 \\
\hline 5-9 anos & 1,29 & 1,31 & 1,18 & 1,41 & 1,09 & 1,14 & 1,20 & 1,09 & 1,03 & 1,21 & 1,35 & 1,23 & 1,24 & 1,55 & 1,21 & 1,49 & 1,12 & 1,10 \\
\hline os & 1,76 & 21 & 1,25 & 1,59 & 1,19 & 1,29 & 1,34 & 1,42 & 19 & 1,42 & 1,57 & 1,54 & 1,63 & 2,04 & 1,75 & 1,65 & 1,90 & 1,36 \\
\hline $15-9$ anos & 1,09 & 1,21 & 1,01 & 1,10 & 1,11 & 0,91 & 1,08 & 1,31 & 1,29 & 1,73 & 2,04 & 2,11 & 2,81 & 4,79 & 4,92 & 4,46 & 5,95 & 4,42 \\
\hline $20-24$ & 1,08 & 1,30 & 1,16 & 1,04 & 0,93 & 0,90 & 1,12 & 1,25 & 1,37 & 1,46 & 2,09 & 2,10 & 2,66 & 4,00 & 4,90 & 4,96 & 6,34 & 4,97 \\
\hline $25-29$ anos & 1,05 & 1,25 & 1,17 & 1,04 & 0,98 & 1,00 & 1,17 & 1,26 & 1,38 & 1,62 & 1,88 & 1,99 & 2,44 & 3,30 & 4,18 & 4,50 & 4,51 & 3,74 \\
\hline os & 1,08 & 1,14 & 1,30 & 1,28 & 1,21 & 1,22 & 1,37 & 1,49 & 1,56 & 1,73 & 2,12 & 1,88 & 2,16 & 2,76 & 3,80 & 3,62 & 3,55 & 3,19 \\
\hline $35-39$ anos & 1,25 & 1,39 & 1,36 & 1,35 & 1,18 & 1,19 & 1,40 & 1,32 & 1,49 & 1,73 & 1,99 & 1,78 & 2,07 & 2,52 & 3,17 & 3,24 & 2,85 & 2,90 \\
\hline os & 1,38 & 1,39 & 1,51 & 1,43 & 1,48 & 1,50 & 1,45 & 1,40 & 1,62 & 1,78 & 1,93 & 1,95 & 1,99 & 2,33 & 2,56 & 2,86 & 2,46 & 2,42 \\
\hline $45-4 \varsigma$ & 1,66 & 1,54 & 1,60 & 1,55 & 1,39 & 1,44 & 1,51 & 1,51 & 1,55 & 1,69 & 1,90 & 1,82 & 1,98 & 2,16 & 2,31 & 2,34 & 2,33 & 2,14 \\
\hline $50-5$ & 1,78 & 1,65 & 1,73 & 1,57 & 1,60 & 1,46 & 1,47 & 1,52 & 1,64 & 1,68 & 1,82 & 1,92 & 1,96 & 2,06 & 2,10 & 2,17 & 2,13 & 2,12 \\
\hline OS & 1,67 & 1,41 & 1,47 & 1,58 & 1,63 & 1,56 & 1,53 & 1,63 & 1,65 & 1,73 & 1,78 & 1,73 & 1,92 & 2,09 & 2,03 & 2,05 & 1,96 & 2,01 \\
\hline $60-64$ & 1,52 & 1,67 & 1,80 & 1,55 & 1,59 & 1,58 & 1,56 & 1,59 & 1,53 & 1,72 & 1,82 & 1,73 & 1,85 & 1,98 & 1,90 & 1,96 & 1,87 & 1,98 \\
\hline nos & 1,47 & 1,70 & 1,51 & 1,59 & 1,50 & 1,46 & 1,52 & 1,57 & 1,55 & 1,66 & 1,67 & 1,75 & 1,69 & 1,79 & 1,91 & 1,90 & 1,88 & 1,91 \\
\hline $70-74$ anos & 1,49 & 1,51 & 1,37 & 1,47 & 1,36 & 1,38 & 1,40 & 1,40 & 1,37 & 1,47 & 1,60 & 1,59 & 1,62 & 1,70 & 1,69 & 1,79 & 1,79 & 1,81 \\
\hline $75-79$ anos & 1,53 & 1,63 & 1,28 & 1,37 & 1,30 & 1,33 & 1,31 & 1,31 & 1,32 & 1,39 & 1,44 & 1,45 & 1,45 & 1,53 & 1,57 & 1,56 & 1,63 & 1,63 \\
\hline 80 anos e mais & 1,13 & 1,16 & 1,30 & 1,37 & 1,29 & 1,19 & 1,19 & 1,06 & 1,01 & 1,11 & 1,17 & 1,21 & 1,20 & 1,21 & 1,21 & 1,25 & 1,35 & 1,28 \\
\hline
\end{tabular}

Fonte: Fundação Sistema Estadual de Análise de Dados - Seade; Departamento de Informática do Sistema Único de Saúde Datasus; Centro de Desenvolvimento e Planejamento Regional - Cedeplar/UFMG.

Nota: Quanto mais escuro, maior é a desvantagem masculina com relação à feminina. 
jovens aumenta de um período para outro (Gráfico 4). Em 1980, aparece o primeiro pico nas idades jovens (15 a 19 anos). No entanto, o restante da curva acompanha

\section{GRÁFICO 3}

\section{Padrão etário do diferencial na mortalidade por sexo} Município de São Paulo - 1920-1950

3,5

3,0

2,5

2,0

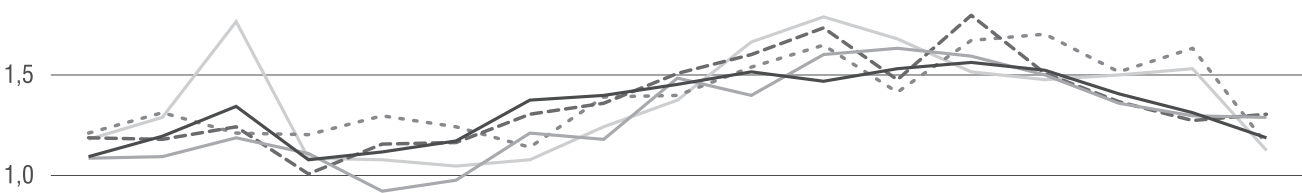

0,5

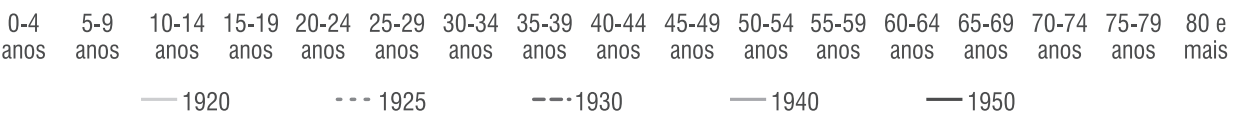

Fonte: Fundação Sistema Estadual de Análise de Dados - Seade; Departamento de Informática do Sistema Único de Saúde Datasus; Centro de Desenvolvimento e Planejamento Regional - Cedeplar/UFMG.

\section{GRÁFICO 4}

Padrão etário do diferencial na mortalidade por sexo Município de São Paulo - 1960-1970

3,5

3,0

2,5

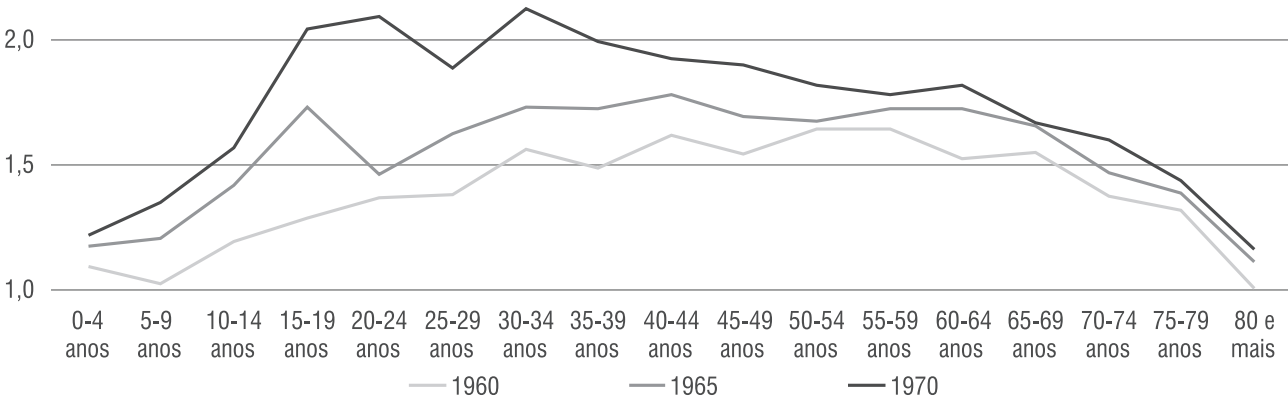

Fonte: Fundação Sistema Estadual de Análise de Dados - Seade; Departamento de Informática do Sistema Único de Saúde Datasus; Centro de Desenvolvimento e Planejamento Regional - Cedeplar/UFMG. 
GRÁFICO 5

Padrão etário do diferencial por sexo na mortalidade Município de São Paulo - 1980-2005

7,0

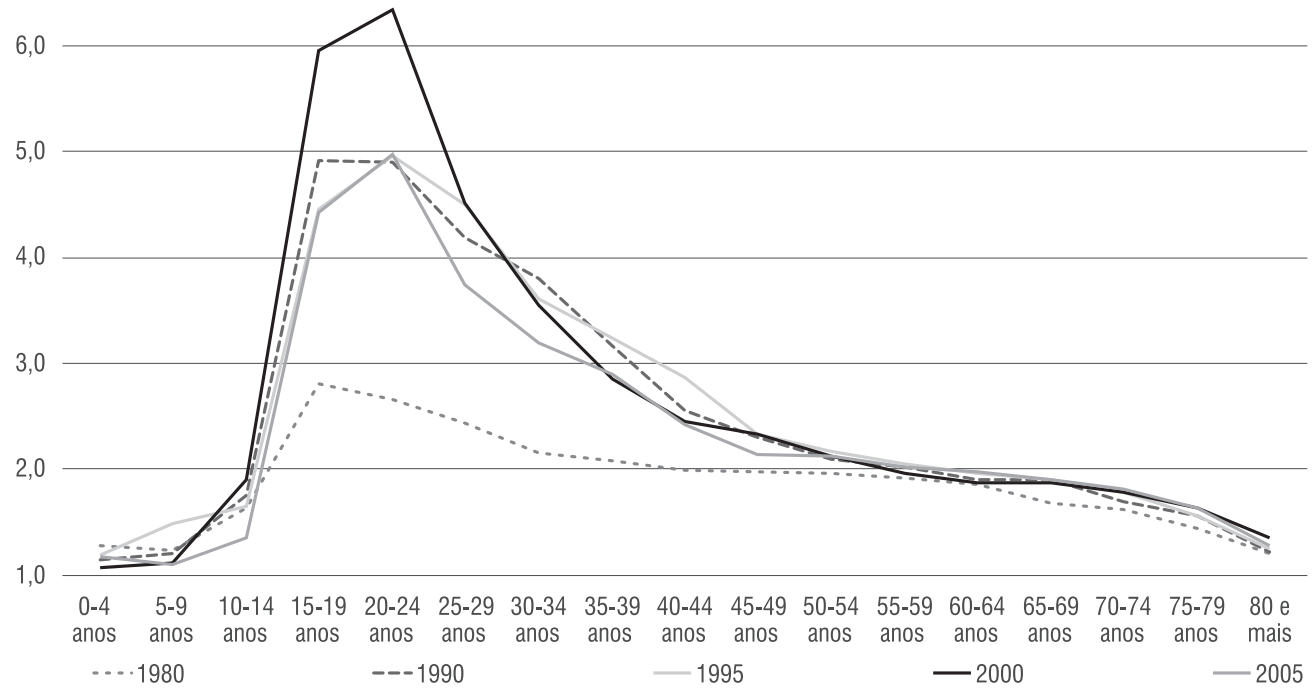

Fonte: Fundação Sistema Estadual de Análise de Dados - Seade; Departamento de Informática do Sistema Único de Saúde Datasus; Centro de Desenvolvimento e Planejamento Regional - Cedeplar/UFMG.

os padrões observados anteriormente. A partir de então, a desvantagem masculina aumenta substancialmente nas idades jovens, apresentando, em 2000, o maior valor. Em 2005, o padrão ainda é semelhante, mas já se observa tendência de redução na desvantagem masculina nas idades jovens, registrando valores com magnitude similar àquela observada na década anterior (Gráfico 5).

Contribuição dos distintos grupos etários para o hiato na mortalidade entre os sexos

Uma vez descritos o comportamento do hiato na esperança de vida por sexo e os padrões etários do diferencial ao longo do período analisado, calcularam-se as contribuições das distintas idades para o diferencial por sexo na esperança de vida ao nascer. O objetivo desta seção é verificar se os grupos etários que apresentam razões por sexo elevadas são, de fato, aqueles que mais contribuíram para o diferencial na esperança de vida ao nascer por sexo e como essa contribuição variou ao longo do tempo.
A primeira análise verifica, de dez em dez anos, quais grupos etários explicam a maior esperança de vida ao nascer feminina. Em seguida, são identificados quais grupos etários foram responsáveis pelo aumento ou diminuição do diferencial na esperança de vida entre homens e mulheres, em alguns períodos selecionados. Para facilitar as análises, trabalhou-se com os seguintes grupos etários: 0 a 4, 5 a 14, 15 a 34, 35 a 59, 60 a 79 e 80 anos e mais.

A comparação das Tabelas 1 e 2 indica que a maior desvantagem masculina nem sempre está associada a uma grande contribuição para o diferencial na esperança de vida. A Tabela 3 apresenta a contribuição dos grupos etários para o diferencial na esperança de vida ao nascer de homens e mulheres residentes no município de São Paulo, de 1920 a 2005. Nas primeiras décadas do século, o grupo etário que mais contribuiu para o diferencial na esperança de vida ao nascer entre os sexos foi o de $0 \mathrm{a}$ 4 anos. Com o passar dos anos, a contribuição deste grupo se reduz substancialmente, de 47,2\%, em 1920, para 2,1\%, em 2005. 
O contrário acontece com o grupo etário aberto, 80 anos e mais, cuja contribuição aumenta de $0,6 \%$ para $9,3 \%$, no mesmo período (Tabela 3 ).

TABELA 2

Contribuição percentual dos grupos etários quinquenais para o diferencial na esperança de vida ao nascer por sexo

Município de São Paulo - 1920-2005

\begin{tabular}{|c|c|c|c|c|c|c|c|c|c|c|}
\hline Grupos etários & 1920 & 1930 & 1940 & 1950 & 1960 & 1970 & 1980 & 1990 & 2000 & 2005 \\
\hline $0-4$ anos & 47,20 & 42,71 & 22,32 & 16,16 & 10,69 & 16,84 & 14,44 & 2,97 & 1,07 & 2,06 \\
\hline 5-9 anos & 3,03 & 1,55 & 1,24 & 1,37 & 0,13 & 0,80 & 0,40 & 0,21 & 0,10 & 0,09 \\
\hline 10-14 anos & 3,66 & 1,18 & 1,51 & 1,67 & 0,68 & 1,01 & 0,91 & 0,73 & 0,67 & 0,30 \\
\hline 15-19 anos & 1,11 & 0,11 & 1,37 & 0,62 & 1,36 & 2,31 & 3,82 & 6,61 & 7,07 & 4,22 \\
\hline 20-24 anos & 1,28 & 2,32 & $-1,36$ & 1,32 & 2,23 & 2,94 & 3,97 & 7,83 & 8,55 & 5,86 \\
\hline 25-29 anos & 0,91 & 2,41 & $-0,40$ & 1,74 & 2,73 & 3,18 & 3,69 & 6,83 & 6,87 & 4,97 \\
\hline 30-34 anos & 1,17 & 3,39 & 3,01 & 3,92 & 4,71 & 4,52 & 3,90 & 6,62 & 5,93 & 4,71 \\
\hline 35-39 anos & 2,92 & 4,11 & 3,02 & 4,68 & 4,56 & 5,10 & 4,81 & 6,45 & 5,35 & 5,11 \\
\hline 40-44 anos & 4,21 & 5,05 & 7,77 & 5,53 & 6,49 & 5,66 & 5,50 & 5,91 & 5,46 & 5,46 \\
\hline 45-49 anos & 6,65 & 5,75 & 6,40 & 7,34 & 7,42 & 6,46 & 6,59 & 6,40 & 6,33 & 6,26 \\
\hline 50-54 anos & 7,43 & 6,91 & 10,50 & 8,71 & 9,87 & 7,31 & 7,45 & 6,61 & 6,61 & 7,91 \\
\hline 55-59 anos & 6,13 & 4,60 & 10,42 & 9,39 & 11,65 & 8,09 & 8,55 & 7,39 & 7,03 & 9,06 \\
\hline 60-64 anos & 4,55 & 8,02 & 11,54 & 11,12 & 11,54 & 9,30 & 9,11 & 7,54 & 7,25 & 9,10 \\
\hline 65-69 anos & 3,63 & 4,88 & 8,63 & 9,62 & 11,08 & 8,71 & 8,19 & 8,20 & 8,09 & 9,54 \\
\hline 70-74 anos & 2,99 & 3,40 & 6,16 & 7,53 & 8,38 & 7,91 & 7,88 & 7,07 & 7,34 & 8,43 \\
\hline 75-79 anos & 2,49 & 1,72 & 3,67 & 4,96 & 6,24 & 5,69 & 5,53 & 6,37 & 6,12 & 7,60 \\
\hline 80 anos e mais & 0,64 & 1,87 & 4,21 & 4,32 & 0,25 & 4,16 & 5,24 & 6,27 & 10,17 & 9,32 \\
\hline e0 fem -e0 masc & 5,71 & 5,95 & 4,17 & 4,61 & 4,75 & 7,42 & 7,82 & 10,49 & 9,78 & 8,19 \\
\hline
\end{tabular}

Fonte: Fundação Sistema Estadual de Análise de Dados - Seade; Departamento de Informática do Sistema Único de Saúde Datasus; Centro de Desenvolvimento e Planejamento Regional - Cedeplar/UFMG.

Nota: Quanto mais escuro, maior é a contribuição do grupo etário para o hiato na esperança de vida.

TABELA 3

Contribuição dos grupos etários para o diferencial na esperança de vida ao nascer por sexo Município de São Paulo - 1920-2005

\begin{tabular}{|c|c|c|c|c|c|c|c|c|c|c|}
\hline Grupos etários & 1920 & 1930 & 1940 & 1950 & 1960 & 1970 & 1980 & 1990 & 2000 & 2005 \\
\hline \multicolumn{11}{|c|}{ Contribuição absoluta } \\
\hline $0-4$ anos & 2,69 & 2,54 & 0,93 & 0,74 & 0,51 & 1,25 & 1,13 & 0,31 & 0,10 & 0,17 \\
\hline 5-14 anos & 0,38 & 0,16 & 0,11 & 0,14 & 0,04 & 0,13 & 0,10 & 0,10 & 0,08 & 0,03 \\
\hline $15-34$ anos & 0,25 & 0,49 & 0,11 & 0,35 & 0,52 & 0,96 & 1,20 & 2,92 & 2,78 & 1,62 \\
\hline 35-59 anos & 1,56 & 1,57 & 1,59 & 1,64 & 1,90 & 2,42 & 2,57 & 3,43 & 3,01 & 2,77 \\
\hline $60-79$ anos & 0,78 & 1,07 & 1,25 & 1,53 & 1,77 & 2,35 & 2,40 & 3,06 & 2,82 & 2,84 \\
\hline 80 anos e mais & 0,04 & 0,11 & 0,18 & 0,20 & 0,01 & 0,31 & 0,41 & 0,66 & 0,99 & 0,76 \\
\hline e0 fem -e0 masc & 5,71 & 5,95 & 4,17 & 4,61 & 4,75 & 7,42 & 7,82 & 10,49 & 9,78 & 8,19 \\
\hline \multicolumn{11}{|c|}{ Contribuição relativa (\%) } \\
\hline $0-4$ anos & 47,20 & 42,71 & 22,32 & 16,16 & 10,69 & 16,84 & 14,44 & 2,97 & 1,07 & 2,06 \\
\hline 5-14 anos & 6,69 & 2,73 & 2,75 & 3,03 & 0,81 & 1,81 & 1,31 & 0,94 & 0,77 & 0,40 \\
\hline 15-34 anos & 4,47 & 8,23 & 2,62 & 7,61 & 11,03 & 12,95 & 15,39 & 27,89 & 28,42 & 19,76 \\
\hline 35-59 anos & 27,34 & 26,44 & 38,11 & 35,65 & 39,99 & 32,62 & 32,90 & 32,76 & 30,77 & 33,80 \\
\hline 60-79 anos & 13,65 & 18,02 & 30,00 & 33,23 & 37,24 & 31,62 & 30,71 & 29,17 & 28,80 & 34,67 \\
\hline 80 anos e mais & 0,64 & 1,87 & 4,21 & 4,32 & 0,25 & 4,16 & 5,24 & 6,27 & 10,17 & 9,32 \\
\hline e0 fem -e0 masc & 100,00 & 100,00 & 100,00 & 100,00 & 100,00 & 100,00 & 100,00 & 100,00 & 100,00 & 100,00 \\
\hline
\end{tabular}

Fonte: Fundação Sistema Estadual de Análise de Dados - Seade; Departamento de Informática do Sistema Único de Saúde Datasus; Centro de Desenvolvimento e Planejamento Regional - Cedeplar/UFMG. 
Em 1920 e 1930, as mulheres viviam, em média, mais do que os homens, principalmente pela vantagem feminina no primeiro grupo etário, mas também pela sobremortalidade masculina entre os 35 e 79 anos. De 1940 a 2005, as mulheres viviam mais principalmente em razão da sobremortalidade masculina entre os $35 \mathrm{e}$ 79 anos. (Tabelas 2 e 3).

A partir de 1960, a contribuição do grupo etário 15 a 34 anos para a vantagem feminina na esperança de vida ao nascer aumentou, até alcançar aproximadamente $29,0 \%$ em 2000. Nesse período, a contribuição do grupo etário 35 a 59 anos permaneceu entre $30,8 \%$ e $40,0 \%$ e a daquele de 60 a 79 anos variou entre $28,8 \%$ e $37,2 \%$. Entre 2000 e 2005, a contribuição atribuída a pessoas de 15 a 34 anos voltou a reduzir, atingindo 19,8\% em 2005 (Tabela 3).

Os dados apresentados na Tabela 4 mostram que, entre 1920 e 1930, o diferencial aumentou pouco, 0,24 ano, e os grupos etários 15 a 34 e 60 a 79 anos foram responsáveis por grande parte desse aumento, ao passo que os dois grupos mais jovens contribuíram no sentido contrário. Entre 1930 e 1940, o diferencial diminuiu aproximadamente dois anos e o grupo etário 0 a 4 anos respondeu por mais de
90\% dessa redução, embora os mais idosos tenham contribuído no sentido contrário. Entre 1950 e 1960, a vantagem feminina na esperança de vida manteve-se aproximadamente constante. No decênio seguinte, o diferencial experimentou um ganho de 2,7 anos, e os grupos que mais contribuíram para esse aumento foram os de 0 a 4 anos e 15 a 79 anos. Na década de 1980, o diferencial também elevou-se em 2,7 anos. Embora o primeiro grupo etário tenha respondido por $31 \%$ da redução do diferencial, a contribuição do grupo etário de 15 a 34 anos teve participação muito pronunciada: $65 \%$. A contribuição dos adultos e idosos, em conjunto, para o aumento do diferencial também foi alta: $66 \%$.

Entre 1990 e 2000, o diferencial apresentou os primeiros sinais de redução, representado principalmente, em ordem de importância, pelas faixas etárias de 35 a 59, 60 a 79,0 a 4 e 15 a 34 anos. Vale ressaltar que o grupo 80 anos e mais contribuiu com $48 \%$ no sentido do aumento do hiato. Entre 2000 e 2005, o decréscimo do diferencial é mais expressivo e explicado, principalmente, pela redução da contribuição do grupo etário 15 a 34 anos (73\%). Entretanto, os adultos e idosos também contribuíram para o estreitamento, exceto a faixa de 60 a 79 anos (Tabela 4).

TABELA 4

Variação do diferencial na esperança de vida ao nascer por sexo Município de São Paulo - 1920-2005

\begin{tabular}{|c|c|c|c|c|c|c|c|c|c|}
\hline Grupos etários & $920-19$ & $1930-194$ & 1940-19 & $1950-196$ & $1960-197$ & 1970-19 & 1980-19 & $1990-2$ & $2000-20$ \\
\hline Variação absolu & & & & & & & & & \\
\hline 0-4 anos & $-0,15$ & $-1,61$ & $-0,19$ & $-0,24$ & 0,74 & $-0,12$ & $-0,82$ & $-0,21$ & 0,06 \\
\hline 5-14 anos & $-0,22$ & $-0,05$ & 0,03 & $-0,10$ & 0,10 & $-0,03$ & 0,00 & $-0,02$ & $-0,04$ \\
\hline 15-34 anos & 0,24 & $-0,38$ & 0,24 & 0,17 & 0,44 & 0,24 & 1,72 & $-0,15$ & $-1,16$ \\
\hline 35-59 anos & 0,01 & 0,02 & 0,05 & 0,26 & 0,52 & 0,15 & 0,86 & $-0,43$ & $-0,24$ \\
\hline 60-79 anos & 0,29 & 0,18 & 0,28 & 0,24 & 0,58 & 0,05 & 0,66 & $-0,24$ & 0,02 \\
\hline 80 anos e mais & 0,07 & 0,06 & 0,02 & $-0,19$ & 0,30 & 0,10 & 0,25 & 0,34 & $-0,23$ \\
\hline Total & 0,24 & $-1,78$ & 0,43 & 0,14 & 2,68 & 0,39 & 2,67 & $-0,71$ & $-1,59$ \\
\hline Variação relativa & (\%) & & & & & & & & \\
\hline 0-4 anos & $-62,10$ & 90,55 & $-43,38$ & $-167,90$ & 27,75 & $-30,93$ & $-30,67$ & 29,14 & $-4,02$ \\
\hline 5-14 anos & $-89,65$ & 2,71 & 5,81 & $-71,87$ & 3,58 & $-8,05$ & $-0,15$ & 3,26 & 2,72 \\
\hline 15-34 anos & 96,15 & 21,40 & 55,75 & 122,72 & 16,35 & 61,58 & 64,52 & 20,53 & 73,11 \\
\hline 35-59 anos & 5,24 & $-0,96$ & 11,88 & 181,60 & 19,57 & 38,20 & 32,34 & 60,22 & 15,15 \\
\hline 60-79 anos & 119,87 & $-10,09$ & 64,50 & 168,29 & 21,65 & 13,62 & 24,66 & 34,40 & $-1,49$ \\
\hline 80 anos e mais & 30,50 & $-3,61$ & 5,44 & $-132,84$ & 11,10 & 25,58 & 9,31 & $-47,55$ & 14,52 \\
\hline Total & 100,00 & 100,00 & 100,00 & 100,00 & 100,00 & 100,00 & 100,00 & 100,00 & 100,00 \\
\hline
\end{tabular}

Fonte: Fundação Sistema Estadual de Análise de Dados - Seade; Departamento de Informática do Sistema Único de Saúde Datasus; Centro de Desenvolvimento e Planejamento Regional - Cedeplar/UFMG. 


\section{Discussão}

Quando comparado aos níveis observados na maioria dos países desenvolvidos, o nível do diferencial de mortalidade por sexo no município de São Paulo foi elevado durante todo o período em análise. Nos países desenvolvidos, quando a esperança de vida feminina variava entre 30 e 40 anos, o hiato na esperança de vida entre os sexos variou de 2 a 4 anos (VALLIN, 1983). No município de São Paulo, a diferença era muito mais elevada, entre 6 e 7 anos. Em nenhum dos países desenvolvidos examinados por Vallin (1983) observou-se redução do diferencial na mortalidade entre os sexos quando a esperança de vida estava entre 45 e 50 anos, sugerindo que o decréscimo, verificado em São Paulo, pode ser uma especificidade do município. A despeito desta característica, a tendência de longo prazo observada em São Paulo assemelha-se, durante o período de aumento sustentado do hiato, àquela observada nos países de origem anglo-saxônica focalizados por Vallin (1983), sobretudo no que tange à estrutura da curva. Entretanto, é importante destacar que, embora o padrão seja semelhante, os níveis do diferencial em São Paulo eram mais elevados.

Alguns autores observaram que, assim como visto em São Paulo, em alguns países, como Itália e Dinamarca, o hiato na mortalidade por sexo também diminuiu no início do período para o qual havia dados disponíveis (GLEl, 2005; GLEl; HORIUCH, 2007), ou seja, na segunda metade do século XIX (1870-1890). No entanto, essa redução foi menos pronunciada do que a observada em São Paulo entre 1935 e 1940. Vale destacar, ainda, que o nível do hiato nestes países (três anos na Dinamarca e 0,5 ano na Itália) era muito menor do que o nível em São Paulo (seis anos).

Tanto nos países desenvolvidos como em São Paulo, após uma fase de aumento sustentado, o diferencial apresentou tendência de declínio. Enquanto em São Paulo o estreitamento ocorreu a partir de 1995, com esperança de vida feminina em torno de 75 anos e um nível do diferencial próximo de 11 anos, na maioria dos países desenvolvidos, a inversão da tendência ocorreu nos anos
1970, 1980 e 1990, quando o nível do hiato variava entre 6 e 8 anos (GLEI, 2005; GLEI; HORIUCH, 2007) e a esperança de vida ao nascer estava entre 75 e 80 anos (UNITED NATIONS, 2008). Assim, os resultados sugerem que o diferencial de mortalidade por sexo, no município de São Paulo, seguiu a mesma tendência observada nos países desenvolvidos, sobretudo no que diz respeito aos níveis de esperança de vida feminina para os quais houve aumento e redução do diferencial. Entretanto, o processo ocorreu com uma defasagem de aproximadamente 30 anos. Além disso, o nível do diferencial no município foi maior do que aquele experimentado pela maioria das nações desenvolvidas.

O padrão etário da mortalidade diferencial por sexo em São Paulo também foi avaliado nesse trabalho. No Estado de São Paulo, observou-se desvantagem feminina na mortalidade nos anos 1940 (ORTIZ; YASAKI, 1984; FERREIRA; CASTIÑEIRAS, 1996b). Por outro lado, no município de São Paulo, como foi possível visualizar nesse artigo, a desvantagem masculina já era verificada desde 1920, em todos os anos e em praticamente todos os grupos etários. Observou-se, ainda, que a transição da mortalidade foi mais homogênea para as mulheres. De acordo com Ferreira e Castiñeiras (1996b), esse processo ocorreu em diversos países desenvolvidos e em desenvolvimento, mas com intensidade inferior àquela registrada em São Paulo. No caso das mulheres, a sobremortalidade nas idades jovens, constatada apenas nas primeiras décadas do século $\mathrm{XX}$, está geralmente associada à mortalidade materna (WINGARD, 1984; FERREIRA; CASTIÑEIRAS, 1996b). Entre os homens, a distorção nas idades jovens está associada às causas externas (FERREIRA; CASTIÑEIRAS, 1996b; MAIA, 2000; CAMARGOS, 2002; SIMÕES, 2002; WALDVOGEL et al., 2003). Há indícios, portanto, de que as variações ao longo do tempo no diferencial de mortalidade entre os sexos sejam explicadas mais por mudanças na mortalidade dos homens do que das mulheres.

Assim como verificado nas tendências de longo prazo do diferencial na esperança de vida por sexo, parece haver uma 
defasagem na transição do padrão etário da mortalidade diferencial por sexo em São Paulo, quando comparada aos países desenvolvidos. O que se observa no município, até 1950 , aconteceu em países como Espanha, Finlândia, França, Itália e Bélgica, antes da década de 1930 (GLEI, 2005). Entre 1960 e 1970, o padrão etário em São Paulo, em forma de "U" invertido, não foi registrado em muitos países, ao longo da transição do padrão etário, mas se assemelha ao da Finlândia, entre 1945 e 1960 (GLEI, 2005).

A transição do pico da desvantagem masculina para as idades jovens ocorreu nos países desenvolvidos na década de 1950 (GLEl, 2005), ao passo que em São Paulo só aconteceu a partir dos anos 1980. A tendência de estabilização dos picos, observada nos países desenvolvidos nos anos 1980, não foi verificada em período algum em São Paulo. Em contrapartida, o início dos anos 2000 caracterizou-se por reduções na magnitude dos picos, tanto nos países desenvolvidos quanto no município de São Paulo.

Outro aspecto do diferencial de mortalidade por sexo analisado nesse trabalho foi a contribuição dos diferentes grupos de idade para o hiato na esperança de vida ao nascer entre homens e mulheres. $O$ padrão de mudança de tais contribuições, em São Paulo, parece ter acompanhado os processos de transição da mortalidade e epidemiológica. Com a redução nos níveis de mortalidade, verificou-se uma substituição gradual das doenças transmissíveis, que afetam as idades mais jovens, pelas doenças não transmissíveis, que em geral atingem mais adultos e idosos (OMRAM, 2005; PRATA, 1992; FERREIRA; CASTIÑEIRAS, 1996b), entre as quais se destacam aquelas do aparelho circulatório, neoplasias e causas externas (PRATA, 1992; FERREIRA; CASTIÑEIRAS, 1996b).

No caso específico de São Paulo, o aumento progressivo dos riscos de morte entre os jovens adultos, associado às causas externas, teve impacto considerável nos resultados. De fato, este é um fenômeno mundial, mas, como dito anteriormente, chama a atenção a intensidade do processo observado no município (FERREIRA; CAS-
TIÑEIRAS, 1996b). Mesmo assim, o padrão de contribuição do hiato na esperança de vida entre os sexos observado em São Paulo é semelhante àqueles descritos para grande parte dos países desenvolvidos. A principal diferença constatada foi a contribuição do grupo etário 15 a 34 anos, que foi mais elevada em São Paulo do que nos países desenvolvidos, no mesmo período.

Assim como observado nos países desenvolvidos, em São Paulo não há uma relação direta entre a desvantagem masculina, medida pela razão de sexo entre taxas específicas de mortalidade por idade, e a contribuição do grupo etário para o diferencial na esperança de vida ao nascer entre homens e mulheres. No início do século, a contribuição do primeiro grupo etário foi muito elevada, ao passo que a razão foi próxima da unidade.

Da mesma maneira, nos anos recentes, as idades adultas e avançadas tiveram grande impacto no diferencial na esperança de vida entre os sexos, mesmo com a grande desvantagem masculina observada, por meio das razões, nas idades jovens. A contribuição elevada das idades avançadas nos anos mais recentes certamente está associada aos processos de transição da mortalidade e epidemiológica no município, visto que, quando o nível geral de mortalidade é baixo, os óbitos tendem a se concentrar nas idades mais avançadas. Ademais, no Estado de São Paulo, a variabilidade da idade à morte das mulheres é significativamente menor do que a dos homens (GONZAGA, 2008) e é provável que tal comportamento também seja observado no município de São Paulo. Este também é um fator que pode estar contribuindo para aumentar a mortalidade diferencial entre os sexos nas idades mais avançadas.

É importante destacar, entretanto, que a contribuição de determinado grupo etário para o hiato na expectativa de vida ao nascer entre os sexos não depende apenas da distribuição de óbitos por idade. Ela é determinada pela diferença entre as taxas específicas de mortalidade feminina e masculina (quanto maior a diferença, maior a contribuição), pela posição do grupo etário (quanto mais jovem, maior é a contribuição 
de uma dada diferença entre taxas específicas para a diferença na esperança de vida) e pela mortalidade nos grupos etários anteriores, visto que dela depende o número de sobreviventes do grupo etário em questão (UNITED NATIONS, 1988).

Assim, embora a concentração dos óbitos nas idades mais avançadas favoreça a contribuição desses grupos etários para o diferencial na esperança de vida por sexo, a posição deles desfavorece, visto que o impacto na esperança de vida ao nascer é maior, quanto mais jovem for o grupo etário. Em contrapartida, a contribuição dos jovens, que é menor do ponto de vista da distribuição dos óbitos por idade, tem a vantagem da posição do grupo etário.

Os resultados da variação do diferencial na esperança de vida ao nascer por sexo, ao longo do tempo, sugerem mais algumas considerações. Em primeiro lugar, no início do processo de transição da mortalidade, as idades mais avançadas já contribuíam para o aumento do diferencial na esperança de vida ao nascer. A distribuição dos óbitos nessa época provavelmente desfavorecia a contribuição desses grupos para o diferencial, uma vez que boa parte dos óbitos ainda estava concentrada nas primeiras idades, especialmente entre os menores de um ano. Mesmo assim, a contribuição dos óbitos de pessoas idosas já era relativamente alta.

A despeito de algumas especificidades, essa tendência se manteve até 1980 , quando o aumento progressivo da mortalidade masculina dos jovens adultos alterou o padrão da mortalidade entre os sexos. Nesse período, os óbitos ocorridos entre os grupos etários constituídos por jovens responderam pela maior parte do aumento do diferencial, embora a contribuição dos idosos ainda tenha sido considerável.

Os dois períodos seguintes foram marcados pela redução da mortalidade diferencial entre homens e mulheres. Entre 1990 e 2000, os adultos (35 a 59 anos) foram os que mais contribuíram para essa redução e, no quinquênio seguinte, quando se observou a maior diminuição da mortalidade diferencial entre homens e mulheres, o grupo 15 a 34 anos respondeu por uma parcela significativa da redução, embora a contribuição das idades mais avançadas também tenha sido considerável. Nesse período, com o avanço da transição da mortalidade, a distribuição dos óbitos por idade favoreceu a contribuição das idades mais avançadas, que passaram a concentrar a maior parte dos óbitos.

No Brasil e em suas localidades, especialmente na Região Sudeste, tem se dado muita importância ao papel das causas externas no diferencial na mortalidade entre os sexos, que está diretamente associada ao pico observado nos adultos jovens. A presente análise mostrou que a contribuição de tais grupos etários para o diferencial é pronunciada, mas as idades avançadas também são responsáveis por uma parcela significativa. De fato, o aumento e a subsequente redução do diferencial na esperança de vida por sexo, entre 1980 e 2005, são explicados, em grande parte, pelos grupos etários associados às causas externas, mas, entre 1990 e 2000, o declínio foi explicado pelo grupo 35 a 59 anos. Com o controle das causas externas, é provável que a contribuição das idades mais avançadas para explicar reduções nos diferenciais de mortalidade por sexo aumente ainda mais. Neste sentido, é preciso dar importância também para os grupos em que a contribuição para o diferencial tem se mantido sistematicamente ao longo do tempo: adultos e idosos.

O forte aumento da mortalidade masculina nas idades jovens em São Paulo distorceu o padrão de mortalidade dos homens, o que teve impacto nas tendências do hiato na esperança de vida entre os sexos. Este comportamento também tem sido observado em vários países, mas com intensidade inferior à de São Paulo. Certamente, este é um fator que contribui para as diferenças observadas entre os padrões e tendências do diferencial em São Paulo e daqueles descritos na literatura internacional para as nações desenvolvidas nos anos mais recentes. Neste sentido, seria interessante realizar as mesmas análises desconsiderando as causas externas em São Paulo. Acredita-se que as tendências ficariam mais próximas daquelas descritas para os países desenvolvidos.

Para entender os determinantes das tendências observadas neste trabalho, são 
necessárias análises que considerem o padrão de contribuição das causas de óbito para o hiato na esperança de vida ao nascer entre os sexos. Esta é uma dimensão muito importante para explicar as tendências e os padrões da mortalidade diferencial entre homens e mulheres e consiste em uma possibilidade de ampliação do escopo do presente trabalho. Verificar a mudança da

\section{Referências}

ARRIAGA E. E. Measuring and explaining the change in life expectancies. Demography, Chicago, v. 21, n. 1, p. 83-96, Feb. 1984.

CAMARGO, A. B. M. Mortalidade por causas externas no Estado de São Paulo e suas regióes. Tese (Doutorado) Faculdade de Saúde Pública, Universidade de São Paulo, 2002.

FERREIRA, C. E. C.; CASTIÑEIRAS, L. L. O aumento da violência entre jovens adultos e as transformaçoes no padrão de mortalidade paulista. Boletim Como Vai? População brasileira, Brasília, v. 1, n. 3, p. 6-12, ago./out. 1996a.

. O rápido aumento da mortalidade dos jovens adultos em São Paulo: uma trágica tendência. São Paulo em Perspectiva, São Paulo, v. 10, n. 2, p. 34-41, 1996b.

FUNDAÇÃO SISTEMA ESTADUAL DE ANALISE DE DADOS - SEADE. Esperança de vida aumenta e diferença entre gêneros diminui. São Paulo: Seade, 2006. Disponível em: <http://www.seade.gov.br/produtos/ espvida/espvida jan2006. pdf > . Acesso em: 18 fev. 2009.

GEE, E. M. Gender and death. Encyclopedia of Death And Dying. New York: Macmillan Reference, 2002. Disponível em: <http:// www.deathreference.com/En-Gh/Genderand-Death.html>. Acesso em: 28 fev. 2009.

GLEI, D. A. The sex gap in mortality: historical patterns across twenty-four countries, Tours, Fance: International Union for the Scientific Study of Population, 2005 (Paper to be presented at Section 203: Gender, Health, and Mortality, IUSSP 2005). contribuição das causas de óbito, ao longo do tempo, associada às tendências aqui observadas, poderá contribuir para lançar luz sobre o entendimento dos fatores associados ao diferencial, em cada momento do tempo. Assim, podem ser vislumbradas políticas mais adequadas à redução da diferença entre as esperanças de vida masculina e feminina.

GLEI, D. A.; HORIUCH, S. The narrowing sex differential in life expectancy in high-income population: effects of differences in the age pattern of mortality. Population Studies, London, v. 61, n. 2, p. 141-159, Jul. 2007.

GONZAGA, M. R. Compressão da mortalidade: entendendo a variabilidade da idade à morte na população do Estado de São Paulo, 1980-2005. 2008. Dissertação (Mestrado em Demografia) - Centro de Desenvolvimento e Planejamento Regional, Universidade Federal de Minas Gerais, 2008.

KALBEN, B. B. Why men die younger: causes of mortality differences by sex. North American Actuarial Journal, Schaumburg, v. 4, n. 4, p. 83-111, Oct. 2000.

KITAGAWA, E. Components of a difference between two rates. Journal of the American Statistical Association, New York, v. 50, n. 272, p. 1168-1194, Dec. 1955.

LANGFORD, C.; STOREY, P. Sex differentials in mortality early in the twenty century: Sri Lanka and India compared. Population and Development Review, New York, v. 19, n. 2, p. 263-282, Jun. 1993.

LUY, M. Causes of male excess mortality: insights from cloistered populations. Population and Development Review, New York, v. 29, n. 4, p. 647-676, Dec. 2003.

MAIA, P. B. O impacto da morte violenta na esperança de vida do município de São Paulo e de quatro zonas sócio-econômicas. In: XII ENCONTRO NACIONAL DE ESTUDOS POPULACIONAIS. Anais... Caxambu: Abep, 2000. Disponível em: <http://www.abep. nepo.unicamp.br/docs/anais/pdf/2000/ Todos/saut18_2.pdf>. 
MURTHY, K. P. A comparison of different methods for decomposition of changes in expectation of life at birth and differentials in life expectancy at birth. Demographic Research, Germany, v. 12, n. 7, p. 141-172, April 2005.

OHADIKE, P. O. Evolving indications of mortality differentials by sex in Africa. In: LOPEZ, A. D.; RUZICKA, L. T. Sex differentials in mortality: trends, determinants and consequences. Canberra, Australia: Australian National University, 1983 (Department of Demography Miscellaneous Series, 4).

OLIVEIRA, J. C.; ALBUQUERQUE, F. R. P. C.; SENNA, J. R. X. Breves notas sobre a mortalidade no Brasil no período 20002005. Rio de Janeiro: IBGE, 2006. Nota Técnica.

OMRAN, A. R. The epidemiologic transition: a theory of the epidemiology of population change. The Milbank Quarterly, New York, v. 83, n. 4, p. 731-757, Dec. 2005.

ORTIZ, L. P.; YASAKI, L. M. Aumento do diferencial por sexo da mortalidade no estado de São Paulo. Revista Brasileira de Estudos de População, Campinas, v. 1, n. 1/2, p. 145-170, jan./dez. 1984.

POLLARD, J. H. Some methodological issues in the measurement of sex mortality patterns. In: LOPEZ, A. D.; RUZICKA, L. T. Sex differentials in mortality: trends, determinants and consequences. Canberra, Australia: Australian National University, 1983 (Department of Demography Miscellaneous Series, 4).

PRATA, P. R. A transição epidemiológica no Brasil. Cadernos de Saúde Pública, Rio de Janeiro, v. 8, n. 2, p. 168-175, abr./jun. 1992.

PRESTON, S. H.; WANG, H. Sex mortality differences in the United States: the role of cohort smoking patterns. Demography, Chicago, v. 43, n. 4, p. 631-646, Nov. 2006.

SÁNCHEZ, H. B.; PRESTON, S. H. A new method for attributing changes in life expectancy to various causes of death, with application to the United States. Philadelphia: University of Pennsylvania, 2007 (PSC Working Paper Series, 07-01).
SHRESTHA, L. Population aging in developing countries. Health Affairs, Millwood, v. 19, n. 3, p. 204-212, May/Jun. 2000.

SIMÕES, C. C. S. Perfis de saúde e mortalidade no Brasil: uma análise de seus condicionantes em grupos populacionais específicos. Brasília: Opas, 2002.

GONZAGA, M. R. Compressão da mortalidade: entendendo a variabilidade da idade à morte na população do Estado de São Paulo, 1980-2005. 2008. 112 f. Dissertação (Mestrado em Demografia) Centro de Desenvolvimento e Planejamento Regional, Universidade Federal de Minas Gerais, 2008.

SIVIERO, P. C. L. Níveis e padrões do diferencial de mortalidade por sexo no município de São Paulo, 1920 a 2005. 2009. 131 f. Dissertação (Mestrado em Demografia) - Centro de Desenvolvimento e Planejamento Regional, Universidade Federal de Minas Gerais, 2009.

TROVATO, F. Narrowing sex differential in life expectancy in Canada and Austria: comparative analysis. In: VIENNA INSTITUTE OF DEMOGRAPHY. Vienna yearbook of population research. Vienna, Austria: Vienna Institute of Demography, 2005, p. 17-52.

UNITED NATIONS. Levels and trends of mortality since 1950: a joint study by the United Nations and World Healyh Organization. New York: United Nations, 1982.

Mortality and the demographic impact of HIV/Aids. In: UNITED NATIONS. World population prospects: the 2004 revision. [S.I.]: United Nations, 2005. Disponível em: <http://www.un.org/esa/population/ publications/WPP2004/2004Highlights_ finalrevised.pdf $>$. Acesso em: 23 jan. 2009.

Mortality and the demographic impact of HIV/Aids. In: UNITED NATIONS. World population prospects: the 2006 revision. [S.I.]: United Nations, 2007 (Working Paper, ESA/P/WP, 202). Disponível em: <http://huwu.org/esa/population/ publications/wpp2006/WPP2006 
Highlights_rev.pdf $>$. Acesso em: 23 jan. 2009.

Patterns of sex differential in mortality in less developed countries. In: LOPEZ, A. D.; RUZICKA, L. T.; AUSTRALIAN NATIONAL UNIVERSITY. Sex differentials in mortality: trends, determinants and consequences. Camberra: Australian National University, 1983 (Miscellaneous series/Australian National University, 4).

Sex differentials in life expectancy and mortaity in developed countries: an analysis by age groups and causes of death from recent and historical data. Population Bulletin of the United Nations, New York, n. 25, p. 65-107, Apr. 1988.

. World population prospects: the 2008 revision. Population Database. United Nations Population Division. Disponível em: <http://esa.un.org/unpp/index. asp? panel=2>. Acesso em: 11 jun. 2008.

VALLIN, J. Mortalidade, sexo e gênero. In: PINNELLI, A. (Org.). Gênero nos estudos de população. Campinas: Abep, 2004. p. 15-54 (Coleção Demographicas, 2).

Sex patterns of mortality: a comparative study of model life tables and actual situations with special reference to the cases of Algeria and France. In: LOPEZ, A. D.; RUZICKA, L. T. Sex differentials in mortality: trends, determinants and consequences. Camberra: Australian National University, 1983. (Miscellaneous series/Australian National University, 4).

WALDVOGEL, B. C. et al. Projeção da população paulista como instrumento de planejamento. São Paulo em Perspectiva, São Paulo, v. 17, n. 3/4, p. 67-79, jul./dez. 2003.

WINGARD. The sex differential in morbidity, mortality and lifestyle. Rev. Public Health, v. 5, p. 433-158, May 1984.

ZANFONGNON, R.; BOUBEAU, R. Sex differential in life expectancy at birth in Canada, 1921-2004: provincial variations. Canadá: Policy Research Initiative/ Government of Canada, 2008.

\section{Resumen}

Diferenciales de mortalidad: niveles y patrones según sexo en el municipio de São Paulo de 1920 a 2005

El objetivo de este trabajo es analizar, de forma sistemática, los niveles y patrones diferenciales de mortalidad entre sexos en el municipio de São Paulo, a lo largo de 85 años, de 1920 a 2005. Se utilizan tres indicadores en el análisis: el intervalo en la esperanza de vida al nacer; la razón de sexo entre tasas específicas de mortalidad por edad; y la contribución de las diferentes edades al intervalo en la esperanza de vida al nacer, en base al método de descomposición de la diferencia entre esperanzas de vida al nacer, propuesto por la ONU (1982). De manera general, las tendencias del período observadas en el municipio de São Paulo son semejantes a aquellas verificadas en países desarrollados, con algunas especificidades. En cuanto a la tendencia a largo plazo del nivel de diferencial en la mortalidad por sexo, se observa un desfase temporal de 30 a 50 años. El inicio del proceso de transición del patrón de edad de la mortalidad diferencial entre hombres y mujeres fue tardío, sin embargo, recientemente, los cambios han sido semejantes a los de los países desarrollados. Asimismo, el análisis de la contribución de las diferentes edades al intervalo en la esperanza de vida al nacer por sexo indica que la reducción del diferencial observada en el último quinquenio fue explicada, principalmente, por la disminución de la mortalidad masculina en las edades jóvenes. No obstante, la reducción en el riesgo de morir entre adultos y ancianos también contribuyó a una proporción significativa (cerca de un $30 \%$ ) del decremento del diferencial de mortalidad por sexo en el período. En este sentido, los resultados aquí presentados sugieren que el comportamiento futuro de los diferenciales de mortalidad por sexo dependerá, en mayor medida, de la heterogeneidad en el riesgo de morir en edades avanzadas.

Palabras-clave: Diferencial de mortalidad por sexo. Descomposición. Municipio de São Paulo. 


\begin{abstract}
Mortality differentials: levels and patterns according to sex in the city of São Paulo from 1920 to 2005

The aim of this study is to systematically analyze levels and patterns of sex differential in mortality rates in the city of São Paulo for a period of 85 years (1920-2005). Three indicators are used: the hiatus in life expectancy at birth; ratio between sexes among specific mortality rates by age; contribution of different ages in the hiatus in life expectancy at birth, based on the method of decomposing difference of life expectancy at birth proposed by the UN (1982). Generally, period trends observed in the city of São Paulo are similar to those found in developed countries, with some specificities. There is a temporal gap of 30 to 50 years in the long-term trend in the sex differential in mortality rate. The onset of the transition from age group to sex diferential was late, but it has become similar to developed countries more recently. Moreover, the analysis of different age contribution to the life expectancy at birth hiatus indicates that the decrease in the differential of the last five years is explained mainly by the decrease in male mortality at young ages. The decrease in death risk among adults and the elderly has also contributed to a significant percentage (about $30 \%$ ) of the decrease in sex differential in mortality rates in this period. Thus, the results here shown suggest that the future behavior of sex differential in mortality rates will depend greatly on the heterogeneity of the death risk in advanced ages.
\end{abstract}

Keywords: Sex differential in mortality rate. Decomposition. City of São Paulo.

Recebido para publicação em 14/05/2010 Aceito para publicação em 14/06/2010 
